Editorial

\section{Is this journal really needed?}

\section{B Pless}

\section{The role of the journal and other matters}

D uring the second world war, propaganda posters carried a message that asked, "Is this trip really necessary?" Their purpose was to persuade people to conserve gasoline. Prompted by the decision to limit free online access to subscribers, some board members and I examined the role this journal plays in fostering injury prevention internationally. We asked, in effect, if this journal was really needed. The answer is a firm "yes".

To assess our contribution I visited the SafetyLit website: Injury Prevention Update (http://www.safetylit.org/). This website has a long list of journals that "are regularly scanned for articles that may be of interest to SafetyLit readers. The journals listed ... either have injury research and prevention as a main focus or print several injury-related articles each year".

The number of journals that meet one or other of these criteria-260-is staggering, unexpected, and probably somewhat misleading. If it were an accurate reflection of the field, the answer to the rhetorical question in the title of this

Table 1 Mainstream journals with general injury prevention focus $(n=5)$

Accident Analysis and Prevention Community Health \& Safety Injury Control and Safety Promotion Injury Prevention Journal of Safery Research editorial would be in some doubt. But it seems that the number is misleading, depending in part on what is meant by "several" because it is difficult to believe that many of those listed publish even a single relevant paper in a typical year. Still, the number of journals is so large that it is a problem for any whose interest in injury prevention is not limited to a single topic such as burns or traffic.

To examine my question in more detail I arbitrarily divided the SafetyLit list into four broad categories: (1) mainstream general injury prevention journals; (2) mainstream specialized injury prevention journals; (3) journals with, at best, a related (indirect) connection to injury prevention; and (4) the remainder, general journals some of which do print some such papers each year. I confess I did not read all 260 journals. In fact, I was unaware of the existence of many of them. Instead I was guided by the titles and by my knowledge of the field.

My approach was liberal. When the title suggested, however remotely, a link I classified that journal as either specialized or related. The results are seen in tables 1-3 and cover about 100 journals. The remaining, group IV "general' journals may be ascertained by visiting SafetyLit and subtracting those listed below. I might add that readers should include policymakers and if the predominantly clinical journals were to be removed, all the lists would be much shorter.

Injury Prevention was created in the hope that it would carry many of the best and most interesting papers. We realized, however, that many authors would prefer to send their truly outstanding papers to "world class" general journals like the $B M J$ or, failing that, to a leading specialized journal. The latter may serve some authors' goals better, for example, when the message is highly specific, although a common reason for rejection is that a paper is judged "not of sufficient interest to readers" of that journal. Nevertheless, it is important that we try to minimize work that is confined to subject or disciplinary silos. We have much to learn from one another and that is a key role for a dedicated but general journal such as ours. Even though Injury Prevention began life with a limited focus on child and adolescent injuries, we eventually saw the error of our ways and decided that the field would be better served by sharing ideas across age groups and across topics.

Our target is general, not specialized. We aim to publish scientifically worthy papers of general interest to researchers and practitioners, whose focus is intentional or unintentional injuries, across the lifecycle. It seems evident that there is great value in having one or more outstanding mainstream journals to ensure that a "sound" paper will elicit a positive response. It is far easier to keep up with important contributions without being forced to do a web trawl periodically if most good papers were published in fewer journals. However, given the wide range of choices authors have (as is evident by the number of journals listed in tables 2 and 3 and the many more "general" journals not listed), it is hardly surprising that the field is confused.

In light of the above, readers may be surprised to find me recommending another journal. But, in a spirit of nurturing the injury prevention field, I want to bring everyone's attention to several excellent papers that appeared in the September 2003 issue of the American Journal of Public Health. The

Table 2 Specialised journals $(n=27)$

Accident and Emergency Nursing Academic Emergency Medicine American Journal of Emergency Medicine American Journal of Sports Medicine Annals of Emergency Medicine Annals of Occupational Hygiene Archives of Suicide Research Burns

Canadian Occupational Safety Child Abuse \& Neglect

Fire Safety Engineering

Fire Safety Journal

Homicide Studies

Human \& Ecological Risk Assessment
Human Factors \& Aerospace Safety

Injury: International Journal of the Care of the Injured

International Archives of Occupational and Environmental Health

International Journal of Occupational \& Environmental Health

International Journal of Occupational Medicine \& Environmental Health

International Journal of Occupational Safety \& Ergonomics

Journal of Agricultural Safety \& Health

Journal of Burn Care \& Rehabilitation

Journal of Child \& Adolescent Substance Abuse

Journal of Interpersonal Violence

Journal of Trauma

Traffic Injury Prevention

Violence Against Women 
Table 3 Indirectly related journals $(n=94)$

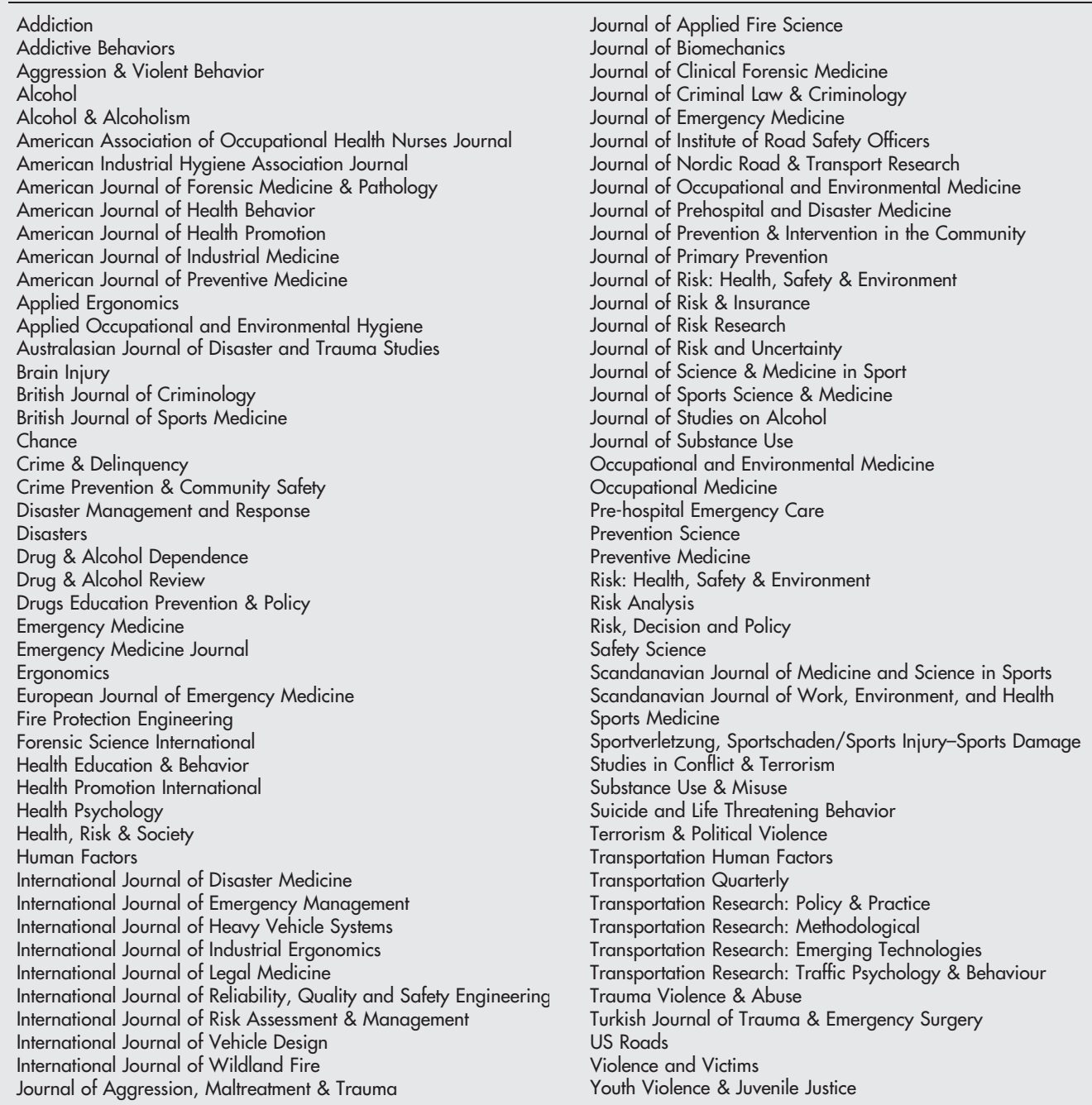

focus is almost exclusively on pedestrian injuries, making this collection unusual for this journal. I was impressed with the editorials and with the papers by Staunton et al, Carter, Carter, and Dannenberg; Retting, Ferguson, and McCartt; Cevero and Duncan; Pucher and Kijkstra; and Schieber and Zegeer. And, while I am being magnanimous in acknowledging other journals, Accident Analysis and Prevention is a perennial favourite in spite of the fact that most papers are traffic related and many use analytic procedures that I cannot understand. Still, it always provides much food for thought.

Bottom line? Our answer to the question in the title is "yes" primarily because we are one of a small number of rigorously peer reviewed, indexed, international, all-age, general injury prevention journals in the field. I hope that we are better read and more often cited than our nearest rivals and that we attract more high quality papers. This journal, and perhaps a few others like it, are desperately needed, but in the end all are commercial ventures and without advertisers who have found a magic pill for preventing injuries, all need continuing support lest, in the words of another World War II metaphor, they just fade away.

\section{REVISITING RISK HOMEOSTASIS}

There are two sides to most coins Although I remain entirely unconvinced that that the risk homeostasis theory has been proven, if it were to be the implications for injury prevention are enormous. This topic has been hotly debated in previous issues of this journal but a conclusive answer about its validity remains uncertain. It is especially open to question if it would apply to children, even if there were better evidence for it among adults.

This prompted my colleagues and me to conduct a pilot study. Our goal was to determine if we could explore the question further by asking children directly about their risk taking behaviour when they consider themselves safer by virtue of their use of protective equipment. It appears our direct approach may be workable but the preliminary answers are disturbing. ${ }^{1}$ They point in the direction that the proponents of the theory suggest and there are other data that tend to support this. ${ }^{2}{ }^{3}$

Nonetheless my position is that the data so far available leave the question of validity wide open. And, it is important to bear in mind that even if the theory holds, it works both ways. Most of the attention has been given to the consequences of safety measures, which, according to the theory, may induce greater risk taking in order to maintain homeostasis. However, the reverse would also apply: that if we judge that we are being exposed to greater risk than our acceptable limits can tolerate, we behave more cautiously.

One of the most powerful arguments against risk homeostasis applying broadly is the consistent decline in death rates from injury in most parts 
of the world. If the theory held, without changes in thermostatic settings, we should expect each gain, technical or otherwise, to be offset by greater risks, thus resulting in no change. Even if it is applicable, it is most likely to affect only a subset of the population, child or adult, who have variable rather than fixed risk tolerances. My hunch is that most people are by nature cautious or adventurous and that these attributes remain unchanged no matter what safety measures are introduced. It is only the remaining group, whose size is unknown but likely to be small, who may be influenced by the phenomenon the theory addresses.

Furthermore, it seems logical to suppose that not all risks are perceived equally. Even children appreciate, instinctively or through experience, that the consequences of a misjudgment about risk resulting from not wearing a helmet are far more serious than those arising from not using wrist guards. Similarly, accepting the risks in ice skating are not the same as accepting the possible consequences of sky diving, skiing in avalanche country, or flying stunt planes. One metric that may influence behaviour is asking, implicitly, "what is the worst that can happen if I do this and am injured?" A broken wrist is not the same as a fractured skull.

I hope readers do not view this as beating a dead horse. The debate is far from resolved and the implications of the theory are potentially so profound that we cannot dismiss it. If it were entirely true, I can well imagine many of us throwing our hands up in despair, crying: Why try?

\section{THANKING REVIEWERS}

Each December I face the daunting task of thanking reviewers. It is daunting because it is so difficult to express my thanks adequately and I always fear someone will be omitted. The list below includes everyone listed on Bench $>$ Press who reviewed one or more papers in the past 12 months. To each of you go my profound thanks as well as the thanks of all our contributors.

Even those whose papers we were forced to reject benefited by your thoughtful and timely comments, as most surely did those who survived the struggle to see their paper appear in print. Contributors are the life blood of any journal, but it is reviewers who ensure that the blood flows properly.

As the obituary on p 295 records, Patricia Waller died this year. Apart from her staggering body of scientific contributions, she was one of our most conscientious and talented reviewers. Her devotion to the journal was beyond question. We are grateful for her work for us and for the field as a whole. It was a privilege to have had her as part of our family. She will be greatly missed.

\section{REVIEWERS 2002-3}

Caroline Acton, Phyllis Agran, Limor Aharonson-Daniel, Bruce Alexander, Shanthi Ameratunga, Craig Anderson, Lee Annest, Susan Aronson, Ruth Azeredo, Deborah Azrael.

Sue Baker, Tara Baker, Michael Ballesteros, Len Banco, Catherine Barber, Lisa Barrios, Les Becker, Dortothy Begg, Larry Berger, Abe Bergman, Polly Bijur, Irene Blackberry, Danilo Blank, Vera Blank, Stephanie Blows, Carme Borrell, Soufiane Boufous, Rebecca Braham, Charles Branas, Stephen Brealey, Ruth Brenner, Robert Brison.

Yvonne Carter, Dawn Castillo, Alfredo Celis, Rina Cercarelli, David Chalmers, Kevin Chan, Albert Chang, Mary Chipman, David Clark, Carolyn Coggan, Donald Cole, Thomas Cole, Richard Compton, Bruce Copley, Tamera Coyne-Beasley, Colin Cryer, Peter Cummings, Kieran Cunningham.

Ronald Danis, Lesley Day, Linda Degutis, Ann Dellinger, Carolyn DiGuiseppi, David DiLillo, T Bella Dinh-Zarr, Mavis Duncanson, Dennis Durbin.

Beth Ebel, Phil Edwards, Rochelle Eime, Robert Ekman, Amy Ernst.

Bruce Farquhar, James Fell, Susan Ferguson, Caroline Finch, Lois Fingerhut, Samuel Forjuoh, Rob Foss, Carolyn Fowler, Shannon Frattaroli.

Susan Gallagher, Susan Gerberich, Andrea Gielen, William Gillespie, Rosa Gofin, Cathy Gotschall, Claude Goulet, Philip Graitcer, Philip Groff, David Grossman, Clare Guse, Kevin Guskiewicz, Bernard Guyer.

Brent Hagel, Steven Hargarten, Sande Harlos, Niki Harre, James Harrison, Jessica Hartos, Roger Haslam, Saidi Hassan, Mike Hayes, David Hemenway, Kitty Hendricks, Ralph Hingson, Jennifer Hootman, Andrew Howard.

Rebecca Ivers, Hugh Jackson, Larry Jackson, Peter Jacobsen, Renee M Johnson, Brian Johnston.

Catherine Karr, Alison Kemp, Denise Kendrick, James King, Joseph Knapik, Olive Kobusingye, Jess Kraus, Matt Kreuter, Etienne Krug.

Lucie Laflamme, Sophie Laforest, John Langley, Garry Lapidus, Frank Leavitt, John LeBlanc, Ronald Lett, Renee Levaque, Guohua Li, Hester Lipscomb, Dana Loomis, Tsung-Hsueh Lu, Jens Ludwig, Peter Lundqvist, Philippe Lunetta, Ronan Lyons.

Colin Macarthur, Diana Macgregor, Murray Mackay, Ellen Mackenzie,
Susan Mackenzie, Alison Macpherson, L H Margolis, Sandra Martin, D L McArthur, Anne McCartt, Roderick McClure, Kara McGee, Gerald McGwin, Elizabeth McLoughlin, Martha Hedjar Medina, Willem Meeuwisse, James Mercy, Angela Mickalide, Mathew Miller, Ted Miller, Charles Mock, Dinesh Mohan, Patrick Morency, Barbara Morrongiello, Seyed Abbas Motevalian, Cam Mustard.

David Nelson, Paul Newacheck, Tan Ngiap Chuan, James Nixon, Terry Nolan, David Nordstrom, Robyn Norton.

Niall O'Connor, Peter O'Connor, Lenora Olson, Joan Ozanne-Smith.

Jocelyn Pedder, Eleni Petridou, Kieran Phelan, Will Pickett, Antonio Plasencia Taradach, Charles Pless, Susan Pollack, David Preusser.

Linda Quan, Parminder Raina, Thomas Rice, Elihu Richter, Fred Rivara, Helen Roberts, Ian Roberts, Gregory Rodgers, Brian Rowe, Carol Runyan.

Jorma Saari, Ellen Schmidt, David Schwebel, Paul Scuffham, Robert Sege, Maria Segui-Gomez, Roy Shephard, Shauna Sherker, Jennifer Sherrard, Jan Shield, Jonathan Sibert, Bruce SimonsMorton, Edith Simpson, Jean Simpson, David Sleet, Gordon Smith, Rick Smith, Hassan Soubhi, Lorann Stallones, Rick Stanwick, Lorena Steenbergen, Malinda Steenkamp, Mark Stevenson, David Stone, Nancy Stout, Jane Stutts, Monica Swahn, Bonnie Swaine.

Stephen Teret, Diane Thompson, James Thomson, David Thurman, Elizabeth Towner, Anne Tursz.

Jon Vernick, Rene Verreault, Donald Voaklander, Robert Voas, Rudinger von Kries.

Patricia Waller, Heather Ward, Lynne Warda, Margaret Warner, Michael Watson, Richard Waxweiler, Daniel Webster, Sharada Weir, Harold Weiss, Jeffrey Weiss, Douglas Wiebe, Allan Williams, Flaura Winston, Garen Wintemute, Tzong-Shiou Woo, Amanda Woods, Craig Zwerling.

Injury Prevention 2003;9:289-291

Correspondence to: Professor I B Pless, Montreal Children's Hospital and McGill University, Montreal, Canada;

barry.pless@mcgill.ca

\section{REFERENCES}

1 Mok D, Gore G, Hagel B, et al. Risk compensation in children's activities: a pilot study. Paediatrics and Child Health. (In press).

2 Morrongiello BA, Major K. Influence of safety gear on parental perceptions of injury risk and tolerance for children's risk taking. Inj Prev 2002;8:27-31.

3 Dilillo D, Tremblay G. Maternal and child reports of behavioral compensation in response to safety equipment usage. J Pediatr Psychol 2001;26:175-84. 